\title{
The Long-Run Stability of European Money Demand
}

\author{
Volker Clausen \\ University of Kiel \\ Jeong-Ryeol Kim \\ University of Kiel
}

\begin{abstract}
The European Central Bank uses a monetary strategy which represents a combination of monetary targeting and direct inflation targeting. In this context, the stability of the long-run European money demand function is widely seen as a precondition for a strategy of monetary targeting. This paper investigates the aggregate demand for money in Europe including those countries representing the initial group in the European Monetary Union. First, we identify stable (in the sense of cointegrated) European money demand functions for M1 as well as for M3. Second, we investigate parameter constancy over time and do not find suggestive evidence of structural instability. Overall, the results provide empirical support for the European Central Bank to target a European monetary aggregate.
\end{abstract}

- JEL Classifications: E41, E52

- Keywords: Money Demand, European Monetary Union, Cointegration

\footnotetext{
*Correspondence Address: Institute of Economic Policy, University of Kiel, Olshausenstr. 40, D-24098 Kiel, Germany (Tel) 49-431-880-3370; (Fax) 49-431-880-4383: (E-Mail) vclausen@bwl.uni-kiel.de

Institute of Statistics and Econometrics, University of Kiel, Olshausenstr. 40, D-24098 Kiel, Germany (Tel) 49-431-880-4297; (Fax) 49-431-880-2637

(C) 2000 - Center for International Economics, Sejong Institution. All rights reserved.
} 


\section{Introduction}

One of the key issues in the debate on the design of European Monetary Union (EMU) concerns the monetary strategy of the European Central Bank (ECB). The choice between direct inflation targeting and monetary targeting rests to a large extent on the properties of the European money demand function. ${ }^{1}$ The stability of money demand is widely regarded as a prerequisite for a regime of monetary targeting. Basically starting with Kremers and Lane (1990), numerous empirical analyzes investigate the properties of European money demand functions.

The previous empirical evidence on European money demand has been surveyed by Browne, Fagan and Henry (1997). Generally, these studies allow for the conclusion that European money demand is a stable function of a few determinants (real income, prices and interest rates). It has to be noted that the term stability has been used in very different meanings. In order to clarify the discussion on the role of the stability of money demand for monetary policy, this paper contrasts four different notions of money demand stability. On the basis of estimated error correction models of European money demand, we illustrate how these different stability concepts can be measured. ${ }^{2}$

Traditional tests for structural stability such as the test by Chow (1960) and the cumulated sum of squares (CUSUM) test introduced by Brown, Durbin and Evans (1975) are based on the assumption of stationary variables. However, the macroeconomic variables underlying money demand regressions are generally non-stationary. Money demand has to be analyzed using the cointegration methodology. Recently, various tests for parameter constancy and structural stability taking account of the non-stationarity and cointegrating relationships of variables have been developed. The main focus of this paper is to apply these tests explicitly designed for cointegrated regression models to the case of European money demand.

In the first step, we identify cointegration relationships describing aggregate European money demand for M1 as well as for M3. We use two differ-

1. See European Monetary Institute (1997) and Deutsche Bundesbank(1988).

2. For a more detailed discussion see also Clausen(1998). For further recent studies on the demand for money in the Euro area see Hayo(1999) and Coenen and Vega(1999). 
ent approaches: the single equation error correction model (SEECM) and the triangular error correction model (TECM). Second, we perform several tests for structural stability. These tests have in common that they are based on the residuals from the fully modified ordinary least squares (FMOLS) estimation method applied to the TECM as suggested by Phillips and Hansen (1990). This class of tests based on the FMOLS residuals has up to now not been applied to the case of European money demand.

The following section contrasts the alternative specifications of error correction models. Section III presents the estimates of European money demand functions for narrow and broad money. In section IV we apply the range of tests for the long-run stability of money demand in Europe. The final section draws conclusions for the monetary policy strategy of the ECB.

\section{Error Correction Models of European Money Demand}

\section{A. Single Equation Error Correction Modeling and Cointegration Tests}

The Goldfeld equation (expressed in logarithms) provides a useful starting point of the analysis. ${ }^{3}$ In equilibrium, real money demand $(m-p)$ is assumed to depend on real income $(y)$ and on the level of interest rates $(r)$ :

$$
(m-p)_{t}^{*}=\beta_{1} y_{t}+\beta_{2} r_{t}+\varepsilon_{t} .
$$

The parameters $\beta_{1}$ and $\beta_{2}$ reflect the income and the interest elasticity of money demand. The demand for narrow money is often assumed to depend on the short-term interest rate; the demand for broad money on the longterm rate. The error term $\left(_{(r}\right)$ reflects unsystematic changes of money demand. In conjunction with the partial adjustment hypothesis:

$$
(m-p)_{t}-(m-p)_{t-1}=\lambda\left[(m-p)_{t}^{*}-(m-p)_{t-1}\right]
$$

we yield the Goldfeld equation:

$$
(m-p)_{t}=\lambda \beta_{1} y_{t}+\lambda \beta_{2} r_{t}+(1-\lambda)(m-p)_{t-1}+\lambda \varepsilon_{t} .
$$

However, the implied dynamics of the Goldfeld equation often prove to be

3. For a lucid discussion of the theoretical background of this equation and the respective empirical evidence see Goldfeld and Sichel (1990). 
too restrictive (Fase(1994b)). Error correction models are now generally used to estimate money demand functions. The general form of a SEECM applied to the case of money demand is:

$$
\begin{aligned}
\Delta(m-p)_{t} & =\bar{b}\left[(m-p)-\beta_{1} y-\beta_{2} r\right]_{t-1}+\sum_{j=1}^{p} b_{j} \Delta(m-p)_{t-j} \\
& +\sum_{j=0}^{q} a_{j} \Delta y_{t-j}+\sum_{j=0}^{s} c_{j} \Delta r_{t-j}+u_{1 t .}
\end{aligned}
$$

Given weak exogeneity of $y$ and $r$, the SEECM can be efficiently estimated by ordinary least squares (OLS). Cointegration can be tested by means of a standard $t$-test on the loading parameter $\bar{b}$. This test for cointegration will be called the $t_{E C M}$-test. It is more efficient and more powerful than the Dickey-Fuller test applied to the residual from the static regression in the twostage Engle-Granger procedure. The underlying distributions for the $t_{E C M}$ statistic are non-standard and presented in Kremers, Ericsson and Dolado (1992). In the case of model (4), the critical value at the $5 \%$ level of significance is -2.02 . The long-run parameters and the corresponding standard errors can be obtained conveniently from the instrumental variable estimation of the Bewley-transformation of (4) (see Wickens and Breusch (1988)).

\section{B. Triangular Error Correction Modeling and Fully Modified OLS}

Phillips(1991) designs a TECM in which - as in the case of the SEECM the causal directions in the cointegrated system are motivated by economic theory. Endogenous and exogenous variables are specified a priori. The difference between the two approaches is that the SEECM explicitly incorporates short-run dynamics while the TECM captures only the long-run relationship. Specified as a TECM, the money demand function takes the following form:

$$
\begin{aligned}
(m-p)_{t} & =\beta_{1} y_{t}+\beta_{2} r_{t}+u_{1 t}, \\
y_{t} & =y_{t-1}+u_{2 t}, \\
r_{t} & =r_{t-1}+u_{3 t},
\end{aligned}
$$


where $\left[u_{1 t}^{\prime} u_{2 t}^{\prime} u_{3 t}^{\prime}\right]^{\prime} \equiv u_{t}=e_{t}-\theta e_{t-1}$ with $e_{t} \sim N\left(0, \Sigma_{e}\right) ; u_{t} \sim N\left(0, \Sigma_{u}\right)$; and $\theta$ being a $(3 \times 3)$-parameter matrix for the moving average of order of one. Phillips and Hansen (1990) develop the semi-parametric FMOLS estimation procedure to estimate the cointegrating parameter vector $\& \beta \equiv\left[\beta_{1} \beta_{2}\right]^{\prime}$. Define the matrices $\Omega=\lim _{T \rightarrow \infty} \frac{1}{T} \Sigma_{i=1}^{T} \Sigma_{j=1}^{T} E\left[u_{j} u_{i}^{\prime}\right]$ and $\Lambda=\lim _{T \rightarrow \infty} \frac{1}{T} \Sigma_{i=1}^{T} \Sigma_{j=1}^{T \rightarrow \infty}\left[u_{j} u_{i}^{\prime}\right]$ with the kernel estimators being:

$$
\begin{aligned}
& \hat{\Omega}=T^{-1} \sum_{t=1}^{T} \hat{u}_{t} \hat{u}_{t}^{\prime}+T^{-1} \sum_{s=1}^{l} w(l, s) \sum_{t=s+1}^{T}\left(\hat{u}_{t-s} \hat{u}_{t}^{\prime}+\hat{u}_{t} \hat{u}_{t-s}^{\prime}\right) \text { and } \\
& \hat{\Lambda}=T^{-1} \sum_{t=1}^{T} \hat{u}_{t} \hat{u}_{t}^{\prime}+T^{-1} \sum_{s=1}^{l} w(l, s) \sum_{t=s+1}^{T} \hat{u}_{t-s} \hat{u}_{t}^{\prime}
\end{aligned}
$$

respectively, where $w(\cdot)$ is a weight function depending on the lag truncation parameter $l$. The estimators $\hat{\Omega}$ and $\hat{\Lambda}$ can be partitioned in conformity with $\quad u_{t}: \hat{\Omega}=\left[\begin{array}{cc}\hat{\omega}_{11} & \hat{\Omega}_{1,2: 3} \\ \hat{\Omega}_{2: 3,1} & \hat{\Omega}_{2: 3,2: 3}\end{array}\right]$ and $\hat{\Lambda}=\left[\begin{array}{cc}\hat{\lambda}_{11} & \hat{\Lambda}_{1,2: 3} \\ \hat{\Lambda}_{2: 3,1} & \hat{\Lambda}_{2: 3,2: 3}\end{array}\right]$

The FMOLS estimator of $\beta$ is then given in (7):

$$
\hat{\beta}^{+}=\left(\sum_{t=1}^{T}\left(m_{t}^{+} x_{t}^{\prime}-\hat{\Lambda}_{2: 3,1}^{+\prime}\right)\right)\left(x_{t} x_{t}^{\prime}\right)^{-1},
$$

where $x_{t}=\left[y_{t}^{\prime} r_{t}^{\prime}\right]^{\prime}$ and $m_{t}^{+}=m_{t}-\hat{\Omega}_{1,2: 3} \hat{\Omega}_{2: 3,2: 3}^{-1}\left[\hat{u}_{2 t}^{\prime} \hat{u}_{3 t}^{\prime}\right]^{\prime}$. The expression $\hat{\Lambda}_{2: 3,1}^{+}=\hat{\Lambda}_{2: 3,1}-\hat{\Lambda}_{2: 3,2: 3} \hat{\Omega}_{2: 3,2: 3}^{-1} \hat{\Omega}_{2: 3,1}$ represents the bias due to the endogeneity of the regressors after the fully modified correction.

The FMOLS estimation is a modified version of OLS to take into account the serial correlation in the cointegration residuals, $u_{1 t}$, and the endogeneity bias caused by the causal influence from the endogenous to the exogenous variables, as well as the cross lagged correlations between the variables, which are specified in the short-run dynamics in the SEECM. Phillips (1990) demonstrates that FMOLS estimation has the same asymptotic efficiency as the maximum-likelihood estimation of the vector autoregressive ECM where at the outset of the modeling all variables are assumed endogenous. 
Estimates of the TECM (5) depend on the lag truncation parameter $l$ included in $\hat{\Omega}$ and $\hat{\Lambda}$. The choice for the Bartlett kernel follows a datadependent plug-in method by Andrews(1991)

1.1447, $\quad\left(\left[\frac{\sum_{i=1}^{k} \frac{4 \hat{e}_{i}^{2} \hat{\sigma}_{i}^{2}}{\left(1-\hat{e}_{i}\right)^{6}\left(1+\hat{e}_{i}\right)^{2}}}{\sum_{i=1}^{k} \frac{\hat{\sigma}_{i}^{2}}{\left(1-\hat{e}_{i}\right)^{4}}}\right] T\right)^{1 / 3}$, for $i=1,2,3$

The expressions $\hat{e}_{i}$ and $\hat{\sigma}_{i}^{2}$ denote the estimates of the autoregressive parameter and of the residual variance for the $i$-th element. Based on this Bartlett kernel, the band with parameters are calculated as 2.7289 for M1 and 5.9961 for M3. Consequently, we select $l=3$ for M1 and $l=6$ for M3.

\section{Tests for Long-Run Parameter Constancy}

The following tests focus on the FMOLS residuals derived from the estimation of the TECM. The FMOLS residuals reflect the nature of the cointegrating relationship while being at the same time free from serial correlation which is the key requirement for residual-based tests. In particular, we apply the test based on the maximum of the sequence of F-statistics (henceforth, SupF test) and the Locally Most Powerful (LMP) test suggested by Hansen(1992), the Lagrange-Multiplier (LM) test by Quintos and Phillips (1993) as well as the CUSUM test by Hao and Inder(1996). ${ }^{4}$

Hansen(1992) introduces an F-test for the constancy of long-run parameters over time. This test basically corresponds with the well-known Chow test or sample split test. It assumes under $H_{1}$ a structural change in the cointegrating relationship. The maximum of the sequence of F-statistics indicates the most likely date of a structural break. Consequently, this test can also be applied in the case of an unknown break point.

Let $\hat{u}_{1 t}^{+}=m_{t}^{+}-\hat{\beta}^{+} x_{t}$ be the FMOLS residuals from equation (5). The SupF test statistic is given by

4. Applications of some of the tests to the case of German money demand are provided in Hansen and Kim(1995). 


$$
\begin{aligned}
& \mathrm{SupF}=\sup _{t / T \in r} F_{T t} \text {, for } \tau \in(0.1) \\
& \text { with } F_{T t}=\operatorname{vec}\left(S_{T t}\right)^{\prime}\left(\hat{\omega}_{12,3} \otimes V_{T t}\right)^{-1} \operatorname{vec}\left(S_{T t}\right) \text {; } \\
& S_{T t}=\sum_{i=1}^{t}\left(x_{i} \hat{u}_{i t}^{+^{\prime}}-\hat{\Lambda}_{2: 3,1}^{+}\right) \\
& V_{T t}=M_{T t}-M_{T t} M_{T T}^{-1} M_{T t}^{\prime} ; \\
& M_{T t}=\sum_{i=1}^{t} x_{i} x_{i}^{\prime},
\end{aligned}
$$

where $\hat{\omega}_{112,3}=\hat{\omega}_{11}-\hat{\Omega}_{1,2: 3} \hat{\Omega}_{2: 3,2: 3}^{-1} \hat{\Omega}_{2: 3,1}$ is the long-run variance of $u_{1 t}$ conditional on $u_{2 t}$. With respect to the choice of $\tau$,we follow Andrews(1991) who suggested the interval $[0.15,0.85]$.

Hansen(1992) also suggests an LMP test under the alternative of no cointegration. Consequently, the SupF test may be applied to check whether there is a one-time change in the cointegrating vector while the LMP statistic tests for the stability of the long-run relationship. The LMP test statistic is

$$
L M P=\operatorname{tr}\left(M_{T T}^{-1}\left(\sum_{t=1}^{T} S_{T t} \hat{\omega}_{12,3}^{-1} S_{T t}^{\prime}\right)\right)
$$

where all symbols have the same meaning as in (9) for the SupF test.

The asymptotic distributions of the SupF and LMP test are non-standard and depend on the structure and number of regressors in the cointegrating vector. The critical values for both cases are tabulated in Hansen (1992).

Hao and Inder (1996) develop a CUSUM test for parameter constancy of cointegration relationships based on FMOLS residuals. Their test procedure extends the CUSUM test based on the OLS-residuals designed by Ploberger and Kramer (1992).

Hao and Inder iffvestigate parameter instability by allowing the cointegrating relationship to depend on time as formulated in (11)

$$
m_{ \pm}=\beta_{t}^{\prime} x_{t}+u_{1 t}
$$

The statistic for the FMOLS residual based CUSUM test is defined as: 


$$
B^{(T)}(\tau)=\frac{1}{\hat{\omega}_{112,3} \sqrt{T}} \sum_{t=1}^{[T \tau]} \hat{u}_{1 t}^{+(T)}
$$

where [ $\cdot$ ] denotes integer part. $B^{(T)}(\tau)$ reflects standardized partial sums of the FMOLS residuals from the full sample, $\hat{u}_{1 t}^{+(T)}$.

The only difference compared with the OLS based CUSUM test designed by Ploberger and Kramer is that here the FMOLS instead of the OLS residuals are used and that the long-run variance estimate $\hat{\omega}_{112,3}^{2}$ replaces the estimated error variance.

Structural stability is rejected for large values of $\sup _{0<r<1 \mid} B^{(T)}(\tau) \mid$ As in the cases of SupF and LMP, the asymptotic distribution of $B^{(T)}(\tau)$ is nonstandard and depends on the covariance structure of regressors. The critical values are provided in Hao and Inder (1996).

Quintos and Phillips (1993) suggest an LM test where under the null of structural stability they assume a time varying stationary process of the cointegrating parameters. Assume that the variation of the long-run parameter follows a Gaussian random walk process $\beta_{t}=\beta_{t-1}+\eta_{t}$ with $\eta_{t} \sim$ iid $N(0, \Sigma$ ), where the initial condition $\beta_{0}$ is not zero. Equation (5) can be re-written as:

$$
\begin{aligned}
m_{ \pm} & =\beta_{0} x_{t}+\left(\sum_{j=1}^{t} \eta_{j}\right) x_{t}+u_{1 t} \\
& =\beta_{0} x_{t}+\omega_{t .}
\end{aligned}
$$

In (13), $w_{t}$ defined as $w_{t}=\left(\sum_{j=1}^{t} \eta_{j}\right)^{\prime} x_{t}+u_{1 t} x_{t}^{\prime}\left(I_{2}, \ldots, I_{2}, 0, \ldots,\right) \eta+u_{1 t}=$ $D L \eta+u_{1 t}$ with $D=\operatorname{diag}\left(x_{1}^{\prime}, \ldots, x_{T}^{\prime}\right)$; and

$$
L=\left(\begin{array}{cccc}
I_{2} & 0 & \ldots & 0 \\
I_{2} & I_{2} & \ldots & 0 \\
\vdots & \vdots & \ddots & \vdots \\
I_{2} & I_{2} & \ldots & I_{2}
\end{array}\right)
$$

The LM test statistic is:

$$
L M=T^{-3} \hat{\omega}^{\prime} D L\left(I_{T} \otimes \hat{\Sigma}^{-1}\right) L^{\prime} D^{\prime} \hat{\omega} / \hat{\sigma}_{0}^{2}
$$

where $\hat{\omega}$ represents the estimated residual under the null, $\hat{\sigma}_{0}^{2}=T^{-1} \hat{\omega}^{\prime} \hat{\omega}$ and 
$\hat{\Sigma}=T^{-1} \Sigma_{t=1}^{T}\left(\Delta x_{t} \Delta x_{t}^{\prime}\right)$ Under the null we have $\Sigma_{\eta}=0$ and therefore $\omega_{t}=u_{1 t}$ which is tested against the alternative $H_{1}: \Sigma_{\eta}>0$. Therefore, under $H_{1}$ is I(1) and no cointegration relation exists. The asymptotic distribution of $\dot{w}_{\eta}$ LM is also non-standard and depends on the nature of regressors in the cointegrating vector.

\section{Empirical Evidence}

This study on European money demand comprises those eleven countries which formed the initial monetary union in 1999. This country group includes Austria, Belgium, Finland, France, Germany, Ireland, Italy, the Netherlands, Portugal and Spain. ${ }^{5}$ We use the monetary aggregates M1 and M3. Data are taken from the International Financial Statistics. The data are quarterly and seasonally adjusted. Whenever available, the series for M3 are for the harmonized aggregate M3H. The database ranges from 1979:1 to 1996:4 where in several cases corrections or extrapolations had to be carried out. ${ }^{6}$ The period of estimation is 1980:1-1996:4.

Aggregation of national series to European series requires rates for currency conversion. This paper uses fixed purchasing power parity rates calculated for 1993 and published in OECD (1995). These conversion rates are used for the aggregation of money stocks, nominal and real income. The aggregate European income figures are used to derive a series for the implied European deflator. The national shares in European income are also used to aggregate the national interest rates. All variables except for interest rates are logarithmized. Figure 1 contains graphs displaying the aggregate European series.

Augmented Dickey-Fuller tests indicate that all variables are nonstationary ${ }^{7}$ so that we analyze money demand within the cointegration methodology.

5. Luxembourg does also belong to this group but remains excluded due to its small quantitative importance.

6. More detailed information on the sources of data is provided in Clausen(1998).

7. Results are available on request. 
Figure 1

Macroeconomic Variables for the Money Demand Function
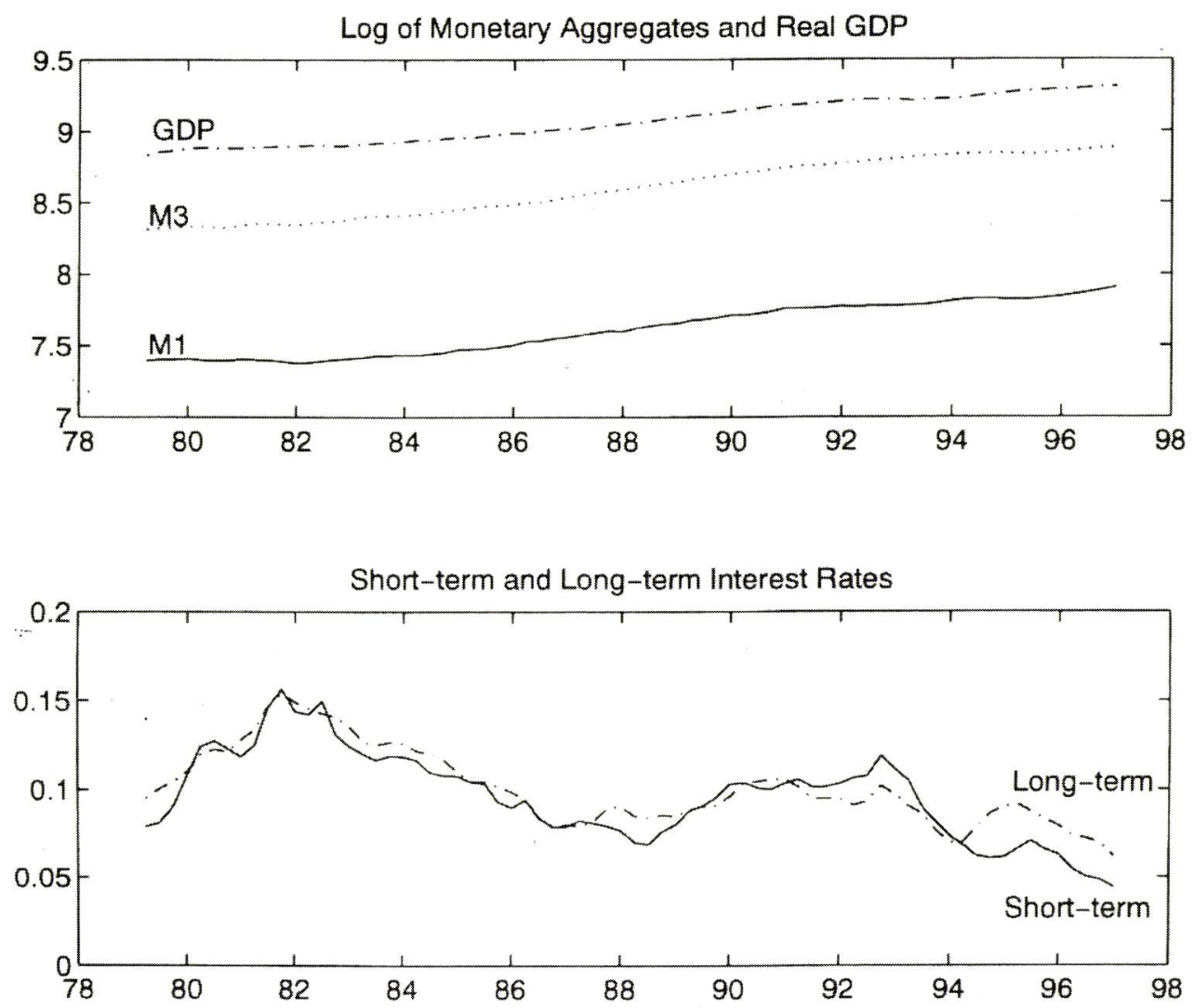

\section{A. Error Correction Models of European Money Demand}

The specification of the empirical SEECM is determined as follows: In our search algorithm, we included real money, real income and short-term as well as long-term interest rates. We specified real money to be the endogenous variable. The dependent variable is $\Delta m_{t}$. Further, we specified first and second lagged real money, $m_{t-1}$ and $m_{t-2}$ as well as real gross domestic product, $y_{t}$, to be included in all specifications. The two lagged money stocks were included since, traditionally, studies on money demand find long adjustment lags. Income was included since it is unlikely to find a cointe- 
grating relationship for money demand excluding a scale variable. Shortterm and long-term interest rates are not restricted to be included in the estimated models. We assume a geometric lag distribution and choose the maximum lag order to be 5 . With 4 variables and 5 lags, 720 regressions have to be carried out. We choose the specification on the basis of the mini$m u m$ of the $t_{E C M}$ statistic. After the deletion of insignificant coefficients we arrive at our final models. Equations (15) and (16) present the results.

We find cointegration in both models of European money demand since the $t_{E C M}$ statistics are below the critical value of -2.02 from Kremers,

Ericsson and Dolado (1992). The equations pass all standard diagnostic tests. Constant terms are insignificant. Real demand for M3 is nearly proportional to real GDP while the real demand for M1 behaves under-proportionally. ${ }^{8}$

Surprisingly, long-term instead of short-term interest rates are identified as the relevant opportunity cost variable in the demand for narrow money. In the demand for broad money, both interest rates enter the cointegration relation with the expected signs.

$$
\begin{aligned}
\Delta m_{1 . t}= & \underset{(-3.76)}{-0.1225}\left[m_{1} \underset{(-138.5)}{-0.8794} y\right]_{t-1}-\underset{(-5.23)}{0.3710} r_{t}^{l} \\
& S . E .: 0.0073 \quad \text { D.W. }: 1.65 \\
& A R(1): x^{2}(1)=1.2946[0.2552] \\
& A R(4): x^{2}(1)=2.7858[0.0951] \\
& A R C H(4): \mathrm{F}(4,57)=0.9778[0.4485] \\
& \text { Normality }: x^{2}(2)=1.5142[0.4690] \\
& x_{i}^{2}: F(6,58)=1.5142[0.4690] \\
& x_{i} * x_{j}: F(9,55)=0.7646[0.6490] \\
& R E S E T: F(1,64)=0.0045[0.8336]
\end{aligned}
$$

8. This may be surprising since income elasticities of narrow money holdings are often found to be unity and for broad money to exceed unity (Fase(1994)). Presumably, the income elasticities are so low because in the sample chosen, interest rates actually follow a downward trend which explains to some extent the upward trend in money holdings. For longer samples in which interest rates are constant on average the estimated income elasticities are expected to be higher. 


$$
\begin{aligned}
& \Delta m_{3 . t}=\underset{(-2.69)}{-0.0496}\left[m_{3} \underset{(-137.3)}{-0.9811} y-\underset{(-1.75)}{2.0836 r^{s}}+\underset{(3.11)}{-4.1541 r^{l}}\right]_{t-1} \\
& +\underset{(4.54)}{0.4331} \Delta m_{3 . t-1}+\underset{(2.80)}{0.0487} \Delta y_{t}-\underset{(-4.56)}{0.3541} \Delta y_{t-1}^{s}
\end{aligned}
$$

$$
\begin{aligned}
& \text { S.E. : } 0.0043 \quad \text { D.W. }: 1.85 \\
& A R(1): x^{2}(1)=0.6986[0.4033] \\
& A R(4): x^{2}(1)=2.4932[0.1143] \\
& A R C H(4): \mathrm{F}(4,54)=0.7669[0.5515] \\
& \text { Normality }: x^{2}(2)=0.9536[0.6208] \\
& x_{i}^{2}: F(12,49)=0.7614[0.6856] \\
& x_{i} * x_{j}: F(9,55)=1.4969[0.1321] \\
& \text { RESET }: F(1,64)=0.99821[0.3217]
\end{aligned}
$$

Concerning the stability of money demand and its relevance for monetary policy it is useful to distinguish four different concepts of stability (Clausen(1998c2)).

Additive stability means that the error term $\left(\varepsilon_{t}\right)$ plays a minor role in the explanation of money demand. Poole(1970) demonstrates that this type of stability has implications for the choice among alternative intermediate targets of monetary policy. Poole notes that additive disturbances in static money demand functions lead to stochastic shifts of the $L M$-curve. In the choice between monetary and interest rate targets, monetary targets will be the more attractive, the higher the additive stability of the $L M$-function relative to the $I S$-function.

Additive stability is evaluated on the basis of the standard error of residuals. The standard errors of the residuals from the error correction models can be directly compared on the basis of the above estimates. By this criterion, the demand for broad money is definitely more stable than the demand for narrow money. ${ }^{9}$

Multiplicative stability refers to the reliability of the estimated parameters in the regression. Multiplicative stability not only requires that coeffi-

9.The same result holds for the standard errors of the residuals from the cointegration relation which are smaller for M3 (0.0323) than for M1 (0.0364). 
cients are significantly different from zero, but also that the uncertainty surrounding the effects is sufficiently small. For example, it appears almost impossible to find an income elasticity of money demand not to be significantly different from zero. However, small standard errors for the income elasticity of money demand are required for the choice of an adequate corridor for the monetary target.

Brainard(1967) analyzes the implications of multiplicative uncertainty for stabilization policy. He concludes that the use of policy instruments ought be the more conservative or cautious, the larger the uncertainty about the effects of policy. This means in the case of monetary policy: The lesser the multiplicative stability (or the higher the multiplicative uncertainty) associated with the interest elasticity of money demand, the more conservative ought to be the change of interest rates in the effort to control the money stock.

Multiplicative stability is evaluated on the basis of the estimated standard errors of the cointegration parameters. These standard errors are taken from the Bewley-transformation of the error correction equation. We find for the long-run income elasticity of M1 (M3) a standard error of 0.0063 (0.0071) such that by this criterion the demand for narrow money is found to be more stable.

Dynamic stability in terms of cointegration is found for both money demand functions. By means of the t-statistics belonging to the error correction terms in (15) and in (16) the null hypothesis of no cointegration, i.e. $H_{0}: \bar{b}=0$ can be rejected. By this criterion both money demand functions are found to be stable. A narrower interpretation of dynamic stability - given that money demand eventually reaches a long-run equilibrium defined by the cointegrating vector - requires the mean adjustment lag in the money demand function to be reliable. In other words, the standard error of the estimated mean adjustment lag is relatively small. This concept of stability refers to the notion of Friedman (1961) that adjustment lags in monetary policy are long and variable. From the perspective of monetary policy direct estimates of the mean adjustment lag and of the corresponding variance are desirable. In the special case of the Goldfeld equation, the Bewley-transformation not only yields the long-run parameters in money demand and their respective standard errors but also - with a negative sign - an exact estimate 
of the mean adjustment lag. In this setup it is possible to evaluate Friedman's argument of long and variable lags directly on the basis of the estimated mean adjustment lag, its variance as well as its stability over time.

In the example of the SEECM, the Bewley-transformation measures the mean adjustment lag arising from the error correction term. In the case of M1, we find a mean adjustment lag of 7.2 quarters with an estimated standard error of 2.2 quarters. In the case of M3, the mean lag derived from the error correction term of 19.1 quarters has a standard error of 7.3 quarters. ${ }^{10}$

Clearly, adjustment lags in M1 are much shorter and substantially less variable than those in the demand for M3. In terms of dynamic stability, the demand for M1 is more stable than the demand for M3.

Structural stability will be evaluated in the following section. A first impression of the sensitivity of the estimated cointegrating vectors can be gained by the comparison of the estimation results based on the SEECM, on the static OLS regression in the Engle-Granger paradigm and on the FMOLS regression. The results are shown in Table (1). Asymptotically, all estimators are bound to generate identical results (Phillips:1991)). While the OLS and the FMOLS estimates are very close to each other, the SEECM results deviate in the case of the interest elasticity rather strongly. This may be explained by the small sample and the influential role of the short-run dynamics in the SEECM.

Table 1

Cointegration Parameters in European Money Demand

\begin{tabular}{|c|c|c|c|c|c|}
\hline Monetary aggregate & \multicolumn{2}{|c|}{ M1 } & \multicolumn{3}{c|}{ M3 } \\
\hline Estimation method & $\beta_{1}$ & $\beta_{2}$ & $\beta_{1}$ & $\beta_{21}$ & $\beta_{22}$ \\
\hline SEECM & 0.8793 & -0.3709 & 0.9801 & 2.0834 & -4.1547 \\
\hline OLS & 0.8608 & -1.9461 & 0.9703 & 0.5328 & -2.4945 \\
\hline FMOLS & 0.8608 & -1.9299 & 0.9675 & 0.3808 & -2.1264 \\
\hline
\end{tabular}

10. In the presence of further short-run dynamics in the SEECM, the true adjustment lag is always under estimated. Since the demand function for M3 also includes several terms reflecting short-run dynamics the overall mean adjustment lag is substantially longer than 20 quarters. 


\section{B. Tests for Parameter Constancy}

The results of the tests for long-run structural stability are summarized in Table 2. for M1 and in Table 3. for M3.

Table 2

Stability Tests of the M1 Cointegration Relation

\begin{tabular}{|l|r|r|r|r|}
\hline \multirow{2}{*}{ Test } & \multirow{2}{*}{ M1 } & \multicolumn{3}{|c|}{ Critical values } \\
\cline { 3 - 5 } & & $10 \%$ & $5 \%$ & $1 \%$ \\
\hline SupF & 15.0653 & 10.6 & 12.4 & 16.2 \\
\hline CUSUM & 0.9127 & 1.0477 & 1.1684 & 1.4255 \\
\hline LMP & 0.2678 & 0.450 & 0.575 & 0.898 \\
\hline LM & 0.0278 & 0.0661 & 0.1052 & 0.2422 \\
\hline
\end{tabular}

Table 3

Stability Tests of the M3 Cointegration Relation

\begin{tabular}{|l|r|r|r|r|}
\hline \multirow{2}{*}{ Test } & \multirow{2}{*}{ M3 } & \multicolumn{3}{|c|}{ Critical values } \\
\cline { 3 - 5 } & & $10 \%$ & $5 \%$ & $1 \%$ \\
\hline SupF & 16.3257 & 15.3 & 17.2 & 21.0 \\
\hline CUSUM & 0.4548 & 0.8381 & 0.9336 & 1.1782 \\
\hline LMP & 1.0381 & 0.680 & 0.834 & 1.18 \\
\hline LM & 0.0978 & 0.1548 & 0.2266 & 0.4320 \\
\hline
\end{tabular}

At a significance level of $5 \%$, the SupF test indicates parameter constancy for M3 but not for M1. The CUSUM test finds the long-run parameters in both money demand equations to be constant over time. The sequences of the CUSUM and SupF test statistics are illustrated in Figure 2. 
Figure 2

\section{SupF-and CUSUM-test for Cointegrating Parameter Constancy}
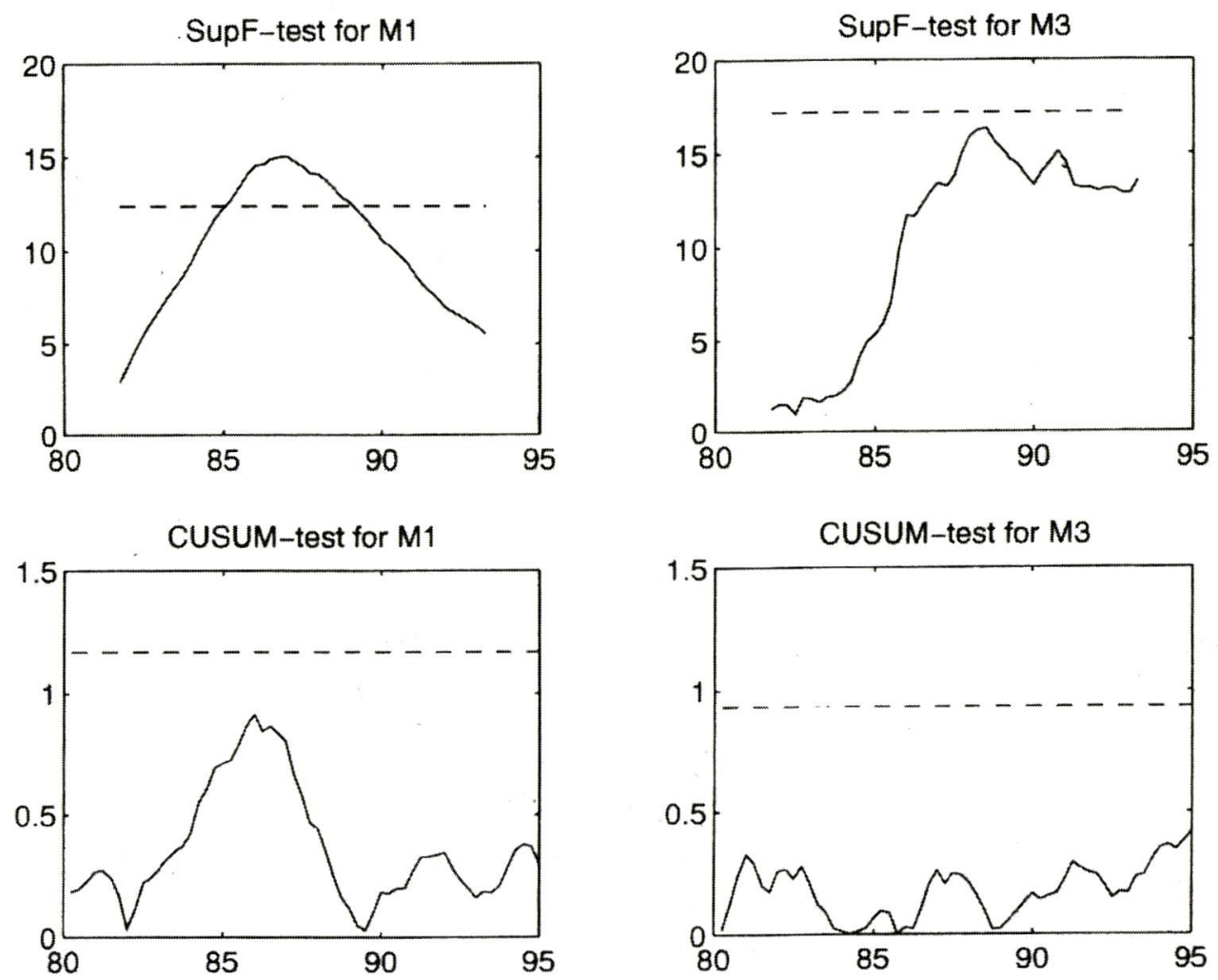

The LMP test provides opposite results: a stable long-run relationship is accepted for M1 but not for M3. The LM test clearly identifies stable longrun relationships in both money demand functions.

The differences in the results for M1 and M3 may be caused by the differences in the number of regressors in the respective cointegrating vectors. The differences in results between the tests for the same monetary aggregate (M1 or M3) may be explained by the small sample and by different speeds of convergence to the asymptotic distributions across tests. Overall, we do not find suggestive evidence against the hypothesis of a stable longrun European money demand. 


\section{Implications for the European Central Bank}

Our results may be summarized as follows: We find cointegrated European money demand functions for M1 as well as for M3. Applying various tests for parameter constancy over time we do not detect suggestive evidence for structural breaks in European money demand. For both monetary aggregates, three out of four tests indicate structural stability. Overall, these results provide support for monetary targeting as a policy strategy of the European Central Bank.

Those prospective EMU member countries which currently monitor monetary aggregates focus in their monetary strategy on broad monetary aggregates (Deutsche Bundesbank(1998)). We do not find the European demand for broad money to be generally more stable than the demand for narrow money. However, it is interesting to note that adjustment lags are substantially longer in the case of broad money. One is tempted to conclude that the broader the chosen monetary aggregate in a monetary targeting regime, the stronger is the case for multi-period monetary targets.

An important question is whether monetary relationships will remain stable after the transition to EMU. Some authors regard empirical studies of European money demand functions before EMU as a fruitless exercise. It may be expected that the transition to EMU constitutes a fundamental structural break altering previous behavioural relationships. Arnold(1994) argues that money demand analyzes prior to EMU are very likely to overestimate the future stability of money demand in Europe. One important reason is that, prior to EMU, money demand shocks in individual member countries are idiosyncratic and tend to cancel each other. After the transition to EMU, these shocks have common sources and tend to be more correlated with each other such that aggregate money demand is likely to be less stable. While these concerns are well founded this does not imply that prior to EMU analyzes of European money demand are useless. After the transition to EMU, at least initially, aggregate European money demand is more likely to turn unstable. If aggregate European money demand was already prior to EMU relatively unstable it can almost be ruled out that after the transition to EMU the ECB chooses monetary targeting as a policy strategy. Furthermore, it is possible to simulate the stability of the European 
demand for money under the assumption that country-specific shocks are perfectly positively correlated. Fagan and Henry (1997) find that the European demand for money is basically as stable as the German demand for broad money even after allowing for a perfect positive correlation of country-specific shocks.

\section{References}

Andrews, D. W. K. (1991), "Heteroscedasticity and Autocorrelation Consistent Covariance Matrix Estimation," Econometrica 59(3); 817-858.

Arnold, I. J. M. (1994), “The Myth of a Stable European Demand," Open Economies Review, 5(3); 249-255.

Brainard, W. (1967), "Uncertainly and the Effectiveness of Policy," American Economic Review, Papers and Proceedings, 57(2); 411-425.

Brown, R. L., Durbin, J. and Evans, J. M. (1975), "Techniques for Testing the Constancy of Regression Relationships over Time," Journal of the Royal Statistical Society, Series B37; 149-163.

Browne, F. X., Fagan, G. and Henry, J. (1997), "Money Demand in EU Countries: A Survey," European Monetary Institute, Frankfurt a.M., Staff Paper No. 7.

Chow, G. C. (1960), "Tests of Equality Between Sets of Coefficients in Two Linear Regressions," Econometrica 28; 591-605.

Clausen, V. (1998), "Money Demand and Monetary Policy in Europe," Review of World Economics 134(4); 712-740.

Coenen, G.; Vega, J.-L. (1999), "The Demand for M3 in the Euro Area," European Central Bank Working Paper No. 6, Frankfurt a.M.

Deutsche Bundesbank (1998), "Monetary Policy Strategies in the Countries of the European Union," Monthly Report 50(1); 33-47.

European Monetary Institute (1997), "The Single Monetary Policy in Stage Three Specification of the Operational Framework," Frankfurt a.M.

Fagan, G.; Henry, J. (1997), “Long-Run Money Demand in the EU: Evidence for Area-Wide Aggregates," European Monetary Institute, Paper presented at ESEM 1997 in Toulouse.

Fase, M. M. G. (1994), "In Search for Stability: An Empirical Appraisal of the Demand for Money in the G7 and EC countries," De Economist 
$142(4) ; 421-454$.

Friedman, M. (1961), "The Lag in Effect of Monetary Policy," Journal of Political Economy 69(5); 447-466.

Goldfeld, S. M., Sichel, D. E. (1990), “The Demand for Money," in: B. M. Friedman and F. H. Hahn (eds.), Handbook of Monetary Economics 1, Amsterdam u.a.; 299-356.

Hansen, B. E. (1992) , "Tests for Parameter Instability in Regressions with

I(1) Processes," Journal of Business and Economic Statistics 10(3); 321335

Hansen, G., Kim, J-R. (1995), "The Stability of German Money Demand: Tests of the Cointegration Relation," Weltwirtschaftliches Archive 131(2); 286-301.

Hao, K.; Inder, B. (1996), "Diagnostic Test for Structural Change in Cointegrated Regression Models," Economics Letters 50(2); 179-187.

Hayo, B. (1999), “Estimating a European Demand for Money," Scottish Journal of Political Economy 46(3); 221-244.

Kremers, J. J. M., Ericsson, N. R. and Dolado, J. J. (1992), "The Power of Cointegration Tests," Oxford Bulletin of Economics and Statistics, 54(3); 325-348.

Kremers, J. J. M., Lane, T. D. (1990), "Economic and Monetary Integration and the Aggregate Demand for Money in the EMS," IMF Staff Papers, $37(4) ; 777-805$.

Organization for Economic Co-Operation and Development (1995), Purchasing Power Parities and Real Expenditures 1993, Paris.

Phillips, P. C. B. (1991), "Optimal Inference in Cointegrated Systems," Econometrica 59(2); 283-306.

Phillips, P. C. B., Hansen, B. E. (1990), "Statistical Inference in Instrumental Variable Regressions with I(1) Processes," Review of Economic Studies 57(1); 99-125.

Ploberger, W., Krämer, W. (1992), “The CUSUM Test with OLS Residuals," Econometrica 60(2); 271-285.

Poole, W. (1970), "Optimal Choice of Monetary Policy Instruments in a Simple Stochastic Macro Model," Quarterly Journal of Economics 84(2); 197-216.

Quintos, C. E., Phillips, P. C. B. (1993), "Parameter Constancy in Cointegrat- 
ing Regressions," Empirical Economics 18(4); 675-706.

Wickens, M. R., Breusch, T. S. (1988), "Dynamic Specification, the Long Run and the Estimation of Transformed Regression Models," Economic Journal 98(390) (Suppl.); 189-205. 